\title{
W.0. Baker Addresses Federation of Materials Societies
}

\author{
The Federation of Materials Societies (FMS) conferred its 1987 \\ National Materials Advancement Award on Dr. William O. Baker \\ during ceremonies in Washington, DC on December 10, 1987. Dr. \\ Baker is a former president of Bell Laboratories and recipient of the \\ 1978 MRS Von Hippel Award. The following is an edited version of \\ Baker's address to the FMS.
}

Now that glasnost can be suitably succeeded by glass-wise (the glassy state), we are nevertheless further alert to a changed world. We are in the conventional condition of wondering, and preparing for the future, while slightly uneasy that it is already here. This does mean that mind-sets and expectations are important, not only for international politics and security, but for industry, economy, technology, and science as well.

Expectations are especially energizing. Indeed, instinctive scientific and technical expectations of President Eisenhower based on discoveries in semiconductors and polymers added crucial impetus to the origins of the present national multidisciplinary laboratory and academic progress in materials research and development. But the Federation of Materials Societies represents a far larger arena than even the vast horizons of materials $R \& D$. Its member societies and their thousands of constituents practice materials science, engineering, production, and economics in ways whose history of achievement, paralleling that of civilization itself, curiously can even be a drag on mind-sets and policies important for materials now and in the next century. The successes in minerals, metals, plastics, textiles, paper and films, finishes, and all are so taken for granted that expectations for the future are often less than they should be.

This seeming anomaly arises because national and international attention are nowadays focused on high-tech enterprises. These are so named since they reflect, both politically and economically, the applications of the scientific and technical shaping of modern affairs. They involve indeed the nucleus, the crystal, the cell-the cosmos-energy, information and communications, biomedicine, and space exploration. But the interesting fact is that...materials have been and will be the essence of each of these vital and dynamic frontiers. So this is a welcome occasion to emphasize that the expectations and strategies of materials technology, engineering and applications must now recognize the intrinsic high-tech nature of the field-of its industry, its educational elements and its governmental, and political and economic impacts. For instance, the President's new Critical Materials Council, under the lively leadership of Bob Wilson, is properly concerned with synthetic and composite structures, reaching far beyond the conventional stockpiling or access to raw materials. The policy being shaped also is sharply aware of the demands on mine and forest to meet exacting design specifications hardly known in the factories of a decade or more ago.

Similarly, in the new mode of recognizing the high-tech responsibilities of engineered materials, the Office of Technology Assessment will be issuing early next year [1988], and has now in its final draft form, an astute and expert articulation of what high-performance composites and polymer solids can do.... Indeed, this report, "Advanced Materials by Design - New Structural Materials Technologies" under the leadership of Dr. Gregg Eyring of the OTA with the OTA Advisory Panel chaired by Mr. Rodney Nichols, is a fine illustration of the positions we are advocating. We urge all here to request it and read it....

Similarly, the National Academy of Engineering, as well as the National Academy of Sciences and the National
Research Council, are strengthening this pattern of advanced education and academic research being joined directly with materials science and engineering in the frontiers of virtually every high-tech activity. The most compelling embodiment of what the pursuit of this theme can achieve appears in the work and composition of the Materials Research Society. In the comparatively short span of its operations, it has added new and excellent dimensions to generation, organization and exchange through publication and meetings of knowledge about matter and its uses.

Thus, the 25th Anniversary of the National Multidisciplinary Laboratory program shows origins and impact from the beginnings in the White House Science Office to the present, which have been documented in the notable volume assembled by Dr. Jesse Ausabel and entitled, Advancing Materials Research. And in the forthcoming COSEPUP study of the National Academy of Sciences updating the COSMAT assessment we chaired with Prof. Morris Cohen a dozen years ago, and in the farsighted program documents for engineering objectives of the National Academy of Engineering, we see mounting evidence of what detailed knowledge can mean to industrial and governmental gains in efficiency, performance, and endurance of matter.

To get such knowledge requires the scope and variety of materials production and usage represented by the component members of the FMS. For this is a powerful way to bring out the future potentials in this field. We can now, with the advantage of these several decades of experience of coupling with high-tech systems, look forward with confidence to the appropriate effort and ingenuity when they are exercised.

This is best illustrated by recalling briefly, some of the endeavors which have already gone along. Even primary schoolbooks now cite the transistor and the semiconductor era as transforming modern life. All of you who have lived through it know that purification and growth of single crystals, such as by W.B. Pfann's zone leveling techniques, are the controlling stages of preparation-whether of power rectifiers, or thin film and integrated circuit elements for computers and communications in all forms. The range of talents involved is reflected in that of the $\mathbf{2 4}$ members of the National Academy of Sciences and the 55 members of the $\mathrm{Na}$ tional Academy of Engineering, that have emerged in our time, from our laboratories [Bell Laboratories] alone, the marked majority have been experts in some phase of materials work. It spreads from solid- 
state physics to molecular beam epitaxial engineering of multiple quantum well structures to circuit design!

In outer space,... ablative nose cones of defending missiles and the heat shields of all manned space and instrumentrecovered vehicles except the shuttle, came from basic studies of polymer dehydrogenation and pyrolytic conversion to polymer carbon networks. These findings then formed the basis later for polymer carbon composites, since we found that the modulus of elasticity of these carbon networks, while less than that of diamond, vastly exceeds that of ordinary reinforcing fibers...

Photonics, a high-tech frontier inspired by the invention of the laser by Schawlow and Townes, is speedily spreading worldwide through materials research and development. Our transfer of silicon chemistry and engineering into historic silicon oxide glass technology has produced ocean-spanning telecommunications cables beginning in 1988. These will be out-doing in cost and capacity even the newest satellite systems. The light guide fibers now developed have tensile strengths approaching $10^{6} \mathrm{psi}$....

No remarks in materials nowadays can omit superconductors. Here the $\mathrm{Nb}_{3} \mathrm{Sn}$ family, discovered by Mathias years ago, have long been in practical use, and perform superbly at liquid helium temperatures, for magnetic resonance imaging, and accelerator magnets. The recent $\mathrm{YBa}_{2}-$ $\mathrm{Cu}_{3} \mathrm{O}_{7-y}$ family of Bednorz and Muller are a poignant reminder that the thousands of new chemical compounds synthesized yearly offer rich regions of materials opportunities.

But every element of materials progress requires combinations of the skills of the Twentieth Century.... This is exactly what it takes to activate the minds and methods which bring new matter, and new meanings, into human reach.

Whether the composites of the Voyager, or in the future Orient Express, the pros-

thetics of joint, kidney, lung or other organ transplant, the packages for fresher foods and assured medicines, enduring dwellings and safer roads, materials will embody the high technology they have already induced in information, communications and national security.

\section{This is a welcome occasion to emphasize that the expectations and strategies of materials tech- nology, engineering and applica- tions must now recognize the intrinsic high-tech nature of the field-of its industry, its educa- tional elements and its govern- mental, and political and economic impacts.}

We are beginning the second phase in the Business/Higher Education Forum of assessing abilities of our country in global competition. This effort, following our report to the President in June of 1983, will be on American know-how. It joins with our report of 1987, to Congressional sponsors, entitled "Making America Work Again." We find that certain technical bases underlie much of the social and economic gains we seek-materials usage and skills is a notable one.... In our intensive work on restoration of literacy and reform of public education, the Project 2061 of the American Association for the Advancement of Science (AAAS), involving science, technology and mathematics, Professor MacVicar, Dr. Rutherford and I find the work of your [FMS] materials societies is providing a special coherence and relevance in learning.

The continuity and interconnections that FMS engenders throughout materials fields are also valuable in allowing necessary time spans of initiative. We remember vividly when S.M. Arnold in our Chemical Laboratory discovered tin whiskers, and aroused the curiosity of our colleagues, J. Galt and C. Herring in the Physics Lab. Thus began decades ago the high-strength crystal fiber era now surging ahead since the mid-Seventies, with $\mathrm{SiC}$ and other special fibers. In a materials history accumulating since the Stone Age, the brief 20th Century years of the solid state enlightenment will not exhaust the time needed to discover and to understand.

...So it is all well-known among your [FMS] constituents that the Information and Communication Age, the space exploration, the components of our national security, have crucial dependence on materials. Likewise, the extraordinary combination of industry and academic roles have both augmented and guided essential governmental policies. This was formulated and documented in the American Society for Metals International lecture on "Materials and Society," a decade ago. ("Materials Proficiency for National Progress," September 21, 1976; Metallurgical Transactions 8A (1977) p. 1205). But today, materials strategies and policies, discussed and forwarded then, invite action, and continue to challenge the FMS community. For example, the Congressional and Executive Branch action on critical materials, and the $\mathrm{Na}$ tional Critical Materials Council of the President now being energized by Bob Wilson, were identified in 1973 then as National Commission on Materials Policy as basic to the new needs of American industrial capabilities. Yet we are only now effectively integrating materials properties with automated and flexible manufacture CAD/ CAM and CIM. Quality assurance when discovered by our associate, Walter Shewhart, in the 1930s was early recognized by its practitioners to involve materials properties more intensely than any other single factor in design. But except for Japanese exploitation, this quantity remains also for future development.

\title{
Advancing Materials Research
}

\author{
From the National Research Council, published by the National Academy Press
}

Highlights recent advances in materials science and engineering $>$ Reviews the first 25 years of the Materials Research Laboratories program - Surveys the current status of materials research in 11 areas - Identifies major policy issues

$$
\begin{aligned}
& 391 \text { pages, hardbound, illustrated, indexed } \\
& \text { \$43-MRS Members \$48-List \$52-Foreign }
\end{aligned}
$$

Order from: Publications Department. Materials Research Society, telephone (412) 367-3012, fax (412) 367-4373. 


\section{Materials Science Titles from Springer-Verlag, Keeping You Abreast of Advancements in Materials Science}

\section{Springer Series in Materials Science}

Vol. 1

\section{Chemical Processing with Lasers}

D. Bäuerle

"Anyone concerned to keep abreast of developments in material processing will find few books more informative or stimulating than this... "CHEMISTRY IN BRITAIN

Provides the first comprehensive survey of the mechanisms and applications of maskless single-step patterning of materials with lasers.

1986/245 pp./88 illus./hardcover \$49.00 ISBN 0-387-17147-9

Vol. 2

Laser-Beam Interactions with Materials

Principlés and Applications

M. von Allmen

"It provides, at a very readable level, a good foundation... highly recommended to both graduate students and materials scientists and engineers." MRS BULLETIN

Examines a wide variety of processes that lasers can induce in materials with applications in such diverse fields as semiconductor annealing, hole drilling, and fusion-plasma production. 1987/232 pp./71 tillus./hardcover \$52.00 ISBN 0-387-17568-7

Vol. 3

Laser Processing of Thin Films and Microstructures

Oxidation, Deposition, and Etching of Insulators

I.W. Boyd

Describes fundamental aspects and practical details of laser processing of thin dielectric films, including deposition, nucleation and growth, oxidation, etching and ablation.

$1987 / 320 \mathrm{pp} . / 77$ illus./hardcover \$59.00 ISBN 0.387-17951.8

Vol. 4

Microclusters

Proceedings of the First NEC Symposium,

Tokyo. Japan, October 20-23, 1986

Edited by S. Sugano, Y. Nishina, and S. Ohnishi

Contents: Shell Models. Electronic Structure. New Experiments. Dynamical Processes. Structural Fluctuations. Larger Microclusters. Semiconductor Clusters.

1987//289 pp./187 illus./hardcover \$56.00 ISBN 0-387-17675-6

In preparation-

Vol. 5

Graphite Fibers and Filaments

M.S. Dresselhaus, K. Sugihara, I.L. Spain,

and H.A. Harts (with contributions by G. Dresselhaus)

Describes the preparation, microstructure and defects, electronic structure, lattice, thermal, mechanical, magnetic, electrical, and high-temperature properties of carbon fibers with particular attention paid to the newly developed vapor-grown fibers.

Vol. 6

Elemental and Molecular Clusters

G. Benedek and T.P. Marttn
Vol. 7

Molecular Beam Epltaxy: Crystallization of

Semiconductor Films from Atomic and Molecular Beams

H. Sitter and M.A. Herman

Vol. 8

Physical Chemistry of, in and

on Silicon

G. Cerofollni and L, Meda

Vol. 9

Tritium and Heltum-3 in Metals

R. Lässer

Vol. 10

Computer Simulation of Ion Solid

Interaction

E. Eckstein

from other Springer-Verlag series -

The Structure of Surfaces II

Proceedings of the Second International Conference, Amsterdam,

The Netherlands, June 22-25, 1987

Edited by J.F van der Veen and M.A. Van Hove

$1988 /$ approx. $608 \mathrm{pp} / 345$ illus/hardcover $\$ 65.00$

ISBN 0.387.18784.7

Springer Series in Surface Sciences, Vol. 11

\section{From Hamiltonians to Phase Diagrams}

The Electronic and Stattstical-Mechanical

Theory of sp-Bonded Metals and Alloys

J. Hafner

Surveys theoretical techniques for the calculation of a pressuretemperature diagram of a pure metal or a composition-temperature diagram of a binary alloy.

1987/404 pp./147 IIus./hardcover \$69.50 ISBN 0-387-17653-5 Springer Series in Solid-State Sciences, Vol. 70

Excitons in Confined Systems

Proceedings of the International Meeting,

Rome, Italy, April 13-16, 1987

Edited by R. Del Sole, A. D'Andrea, and A. Laptcclrella 1988/approx. $256 \mathrm{pp} / 148$ illus./hardcover $\$ 57.50$ (tent.) ISBN 0-387-18707-3

Springer Proceedings in Physics, Vol. 25

To Order: please visit your local scientific/academic bookstore, call our TOLL FREE NUMBER: 1-800-526-7254 (in NJ, 201-348-4033), or send payment, including $\$ 2.50$ for postage and handling, to the address below. Residents of NY, NJ, and CA please add sales tax for books. Personal checks, money orders, and American Express, MasterCard, and VISA are acceptable.

For More Information: please call or write

Springer-Verlag New York, Inc.

Attn: Ken Quinn, Dept. S832

175 Fifth Avenue, New York, NY 10010
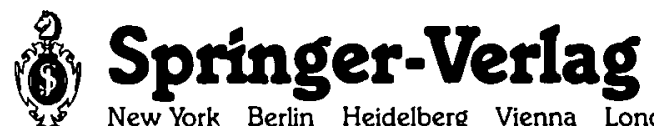

New York Berlin Heidelberg Vienna London Paris Tokyo 